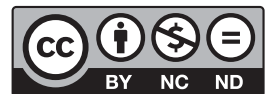

Estudos Teológicos foi licenciado com uma Licença Creative Commons Atribuição - NãoComercial - SemDerivados 3.0 Não Adaptada

http://dx.doi.org/10.22351/et.v58i2.2725

\title{
SACRAMENTOS E ECUMENISMO - QUeSTÕes SOBRE O SIGNIFICAdo, A INSTITUIÇÃO E O NÚMERO DOS SACRAMENTOS ${ }^{1}$
}

\author{
Sacraments and ecumenism - Questions about the meaning, \\ the institution and the number of sacraments
}

Elias Wolff ${ }^{2}$

Resumo: As igrejas distinguem-se umas das outras pelos sinais sacramentais que possuem, considerados constitutivos da própria identidade cristã e eclesial. Nesse aspecto manifestam-se diferenças e também divergências na doutrina cristã e na organização eclesial entre as várias tradições do cristianismo. A questão vai além de ter mais ou menos sacramentos. O ponto controverso é sobre quais são os meios imprescindíveis para fazer a experiência da graça de Cristo. Entre esses meios situam-se os sacramentos. O objetivo deste artigo é analisar algumas das controvérsias existentes na doutrina sacramental das igrejas, a saber, o significado de sacramento, sua instituição em Cristo e o número dos sacramentos. Com o uso do método de análise bibliográfica qualitativa, o artigo verifica como teólogos de diferentes igrejas compreendem essas questões e como elas são trabalhadas no diálogo ecumênico atual. $\mathrm{O}$ artigo conclui que os sacramentos possuem uma dimensão ecumênica no sentido de, por eles, se expressar a fé de todos os cristãos. Para isso urge, porém, desenvolver uma hermenêutica ecumênica dos sinais sacramentais da fé cristã, explicitando sua capacidade de congregar na comunhão da fé todos os que creem em Cristo.

Palavras-chave: Sacramentos. Graça. Igreja. Ecumenismo.

Abstract: The churches differ one from another due to the sacramental signs they have, which constitute their own Christian and church identity. On this regard there are some differences and divergences in the Christian doctrine and in the church organization among various Christian traditions. The point is far from concerning only the number of sacraments. The controversial question is on what are the indispensable means to experience the grace of Christ. Among these means we have the sacraments. The objective of this article is to analyse some of the controversies in the sacramental doctrine of churches, namely, the meaning of sacrament, its institution in Christ and

\footnotetext{
1 O artigo foi recebido em 04 de abril de 2016 e aprovado em 25 de abril de 2017 com base nas avaliações dos pareceristas ad hoc.

2 Doutor em Teologia. Programa de Pós-Graduação em Teologia - PUCPR, Curitiba, PR, Brasil. Líder do Grupo de Pesquisa Teologia, Ecumenismo e Diálogo Inter-religioso (PUCPR). Pesquisador bolsista do CNPq. Contato: elias.wolff@pucpr.br. O presente trabalho foi realizado com apoio da Coordenação de Aperfeiçoamento de Pessoal de Nível Superior - Brasil (CAPES) - Código de Financiamento 001.
} 
the number of sacraments. Through a qualitative bibliographical analysis method, the article verifies how theologians from different churches understand these questions and how they are wrought in the currently ecumenical dialogue. The article concludes that the sacraments have an ecumenical dimension: it is through the sacraments that the faith of all Christians is expressed. However, it is urgent to develop an ecumenical hermeneutic of the Christian faith's sacramental signs, making explicit its capacity to congregate in the communion of faith everyone who believes in Christ.

Keywords: Sacraments. Grace. Church. Ecumenism.

\section{Introdução}

$\mathrm{Na}$ história da igreja, a compreensão teológica dos sacramentos é cercada de controvérsias. Foi árduo o caminho para se obter consenso sobre a instituição dos sacramentos em Cristo, o número dos sacramentos, sua natureza, sua estrutura, sua causa e seus efeitos, sua necessidade para a salvação. Na verdade, um consenso pleno nessas questões nunca foi alcançado entre as diferentes tradições teológicas e litúrgicas do cristianismo. $\mathrm{O}$ que se conseguiu foram apenas acordos circunstanciais e parciais, construídos em meio a fortes querelas na história da teologia sacramental. $\mathrm{O}$ atual contexto ecumênico possibilita às igrejas desenvolverem uma sacramentaria em perspectiva ecumênica, na qual os sacramentos são afirmados como constitutivos da unidade da igreja. Dialogam sobre como elas podem celebrar a comunhão de fé nos mesmos sacramentos. Assim, é importante retomar aqui algumas questões disputadas sobre os sacramentos, como seu significado teológico, sua instituição por Cristo e o número dos sacramentos, e desenvolvê-las em perspectiva ecumênica. Outras questões existentes estão articuladas nessas e dessas decorrem.

\section{A problemática do conceito "sacramento"}

A primeira questão que suscita controvérsias entre as igrejas é como identificar e compreender o que é "sacramento". Esse conceito é vinculado à experiência da graça de Cristo, mas ele é problemático para indicar a forma como a graça é recebida na igreja. O que significa dizer que o sacramento possibilita a experiência da graça? Qual a equivalência entre a graça experimentada e o sinal sacramental utilizado para expressá-la? Qual a diferença entre esse sinal e outros meios que também permitem a comunhão na graça de Cristo? O consenso que se verifica é que "sacramento" no mundo cristão tem origem na concepção de que a salvação que Deus quer dar à humanidade se realiza em Jesus Cristo, o qual atua na igreja através de pessoas, palavras, eventos, sinais, que podem ser ritualmente vividos na comunidade eclesial. Entende-se nisso uma cerimônia cultual, ou ação simbólica, "simbólico-real"3, na qual se

3 VERGOTE, Antoine. La realisation symbolique dans l'expresion cultuelle. La Maison-Dieu, Paris, n. 111, p. 110-131, primeiro trimestre 1972. Também: CHAUVET, Louis-Marie. Du Symbolique au Symbole. Essai sur les sacrements. Paris: Edition du Cerf, 1979. 
manifesta o mistério da presença salvífica de Deus em Cristo e na força do Espírito. Porém essa compreensão global de sacramento não resolve as tensões que surgem quando as igrejas buscam aplicar esse conceito aos sinais/símbolos concretos que creem ter natureza sacramental.

As questões acima apresentadas, entre outras, não são hoje respondidas com simples recorrência às escrituras ou à tradição da igreja. As passagens da Bíblia e da patrística tidas como pilares da sacramentaria precisam ser atualizadas, visando à compreensão dos sacramentos na atualidade e a promoção do diálogo entre as igrejas que buscam consenso sobre os sinais sacramentais da fé cristã. Naturalmente, Tertuliano (m. 220) muito contribuiu traduzindo o termo mysterion (utilizado pelas religiões para designarem suas doutrinas e símbolos) por sacramentum, designando um ato de consagração, um juramento que se expressa por algum sinal exterior. ${ }^{4}$ Agostinho (m. 430) impulsionou a teologia sacramental afirmando que o Deus invisível se revela por sinais visíveis, e esses sinais visíveis (signa) indicam uma realidade invisível (res) à qual se assemelham. ${ }^{5}$ Daqui sua compreensão de sacramento como signo visibile, gratiae invisibile. Na mesma direção segue Teodoro de Mopsuéstia, vinculando o conceito mysterion a sacramentum, como "manifestação sinalizadora e simbólica de coisas invisíveis e inefáveis" ". Enfim, dado o caráter misterioso da ação da graça divina, as ações sagradas da igreja são entendidas como mysteria, enquanto símbolos que representam eficazmente a realidade que simbolizam.

Assim, para expressar o conteúdo da fé cristã, a graça, o símbolo foi associado a sacramento. Mas o conteúdo e o conceito são distintos, a graça de Cristo e o termo sacramento não são a mesma coisa, mesmo se intimamente relacionados. Portanto é uma tarefa teológica complexa justificar a relação entre graça e sacramento. Constata-se, contudo, que há entre as igrejas uma compreensão comum de sacramento, adotando, grosso modo, o ensino dos Padres da Igreja. O consenso está em afirmar que os sacramentos são sinais privilegiados da fé cristã. Mas a divergência aparece na identificação desses sinais sacramentais, na sua concepção teológica, na vivência litúrgica e na organização pastoral. Então algumas igrejas consideram sacramentos aquilo que outras veem apenas um "sacramental", entendendo por esse conceito um sinal que pode remeter a uma realidade sagrada, mas que não possui a natureza de um sacramento propriamente dito, como o Batismo e a Ceia. Dessa forma, a teologia clássica não resolve todas as questões que emergem ao se afirmar os sacramentos como mediações da experiência da graça de Cristo para todos os cristãos de hoje. Isso tem a ver com a questão da instituição dos sacramentos por Cristo.

4 Tertuliano, Ad Martyres, 3.1, apud FABER, Eva-Maria. Doutrina Católica dos Sacramentos. São Paulo: Loyola, 2008. p. 46.

5 AGOSTINHO. A Doutrina Cristã. Livro 1, Cap. 2. 2. ed. São Paulo: Paulus, 2007. p. $42-43$.

6 Teodoro de Mopsuéstia, Homiliae Catecheticae 12,2, apud FABER, 2008, p. 45. 


\section{A instituição dos sacramentos}

\section{Retomando a história}

No período apostólico, os sinais da fé têm uma compreensão mistérica, espiritual e salvífica, não há teoria nem disciplina sacramental definidas, as quais surgem a partir da patrística e se desenvolvem na escolástica. A Bíblia mostra que dois são os principais sinais que testemunham o seguimento de Jesus: o Batismo, que integra na comunidade dos fiéis (At 8.12; 16.33), expressando a conversão a Cristo (Ef 4.5; Rm 6.4), e a Ceia, que permite comungar do corpo do ressuscitado (Mt 26.26; Mc 14.22; Lc 22.19; 1Co 10.16). Esses sinais são considerados pelos primeiros cristãos como suficientes para a vivência do kerigma. Há passagens em que aparece também a imposição das mãos para a recepção do Espírito Santo (At 8.17). Mas esse sinal é muitas vezes ligado ao Batismo, ou feito imediatamente após o rito batismal, e apenas bem mais tarde ele vai se deslocando do Batismo para ter um ritual próprio.?

É no período patrístico que se inicia a construção de uma teologia dos sacramentos, que os insere no mistério de Cristo e na ação do Espírito. O que os Padres pretendiam era ajudar a compreender os sacramentos como celebrações do mistério de Cristo, de onde vem sua força e eficácia. Distinguiam, assim, os sacramentos da fé cristã dos sinais da fé do Primeiro Testamento, apresentando os elementos que os caracterizam como comunicação da graça de Cristo, sua causa e seus efeitos na vida cristã.

O período da escolástica assiste a uma polarização das teses de uma instituição imediata por Cristo de cada sacramento, ou uma instituição mediada pelos apóstolos e a igreja ou, ainda a instituição por Cristo com a promulgação dos apóstolos. ${ }^{8} \mathrm{O}$ Concílio de Trento afirma a instituição dos sacramentos por Cristo e o setenário, sem explicar, porém, a forma dessa instituição. Entende que a "substância" do sacramento foi instituída por Cristo, sem dizer também "em que" consiste precisamente o que Cristo colocou no sinal sacramental, e não deixa claro o que não pode ser mudado no sacramento (porque dado por Cristo) e o que pode ser mudado (como ação da igreja na história). ${ }^{9}$ No período pós-tridentino, afirmou-se que Cristo instituiu os sacramentos in individuo (determinando a substância e as particularidades); in specie (instituindo a matéria e a forma de cada um, mas não os detalhes e sua concretização posterior, que seria da igreja); e in genere (dando-lhes uma eficácia de graça, cabendo à igreja de-

7 MARSILI, Salvatore. Sinais do Mistério de Cristo. Teologia litúrgica dos sacramentos, espiritualidade e ano litúrgico. São Paulo: Paulinas, 2010. p. 239-240.

8 BOROBIO, Gionisio. Da celebração à teologia: que é um sacramento? In: BOROBIO, Gionisio et al. $A$ celebração na Igreja - Liturgia e sacramentologia fundamental. São Paulo: Loyola, 1990. v. I, p. 346. Tomás de Aquino entende que a origem dos sacramentos está em Cristo, afirmando que Cristo tem um "poder de excelência" sobre os sacramentos, pois eles "dependem dos méritos da sua paixão", são "administrados em seu nome" e "santificam através da sua virtude" (Tomás de Aquino. Summa Theologica. Questão LXIV, "Da causa dos sacramentos", Art. III, "Se Cristo, enquanto homem, tinha o poder de produzir o efeito interior dos sacramentos", 1-4: AQUINO, Tomás. Suma Teológica. 2. ed. Caxias do Sul: Livraria Sulina Editora, 1980. Terceira Parte, colunas 4090-4091.

9 Ver essa discussão em BOROBIO, 1990, p. 345-346. 
terminar os elementos físico-visíveis e sua concretização). ${ }^{10}$ Essa última tese é a mais aceita: "Com efeito, os sacramentos instituídos por Cristo não foram dados à Igreja como plenamente constituídos, mas enquanto abertos a uma determinação posterior [...] O importante é que o sacramento se destina à graça e à santificação, fato que só pode ser explicado a partir de Cristo e do seu mistério"11.

A questão exige uma interpretação dos textos bíblicos que vinculam os sacramentos à compreensão da pessoa de Cristo. Tarefa nada fácil, uma vez que a Bíblia não oferece uma exposição detalhada sobre a relação entre Cristo e os sacramentos nem afirma explicitamente que ele instituiu os sacramentos. Essa compreensão se desenvolve na história do cristianismo quando se compreende que a salvação e a vida eterna são mediadas por acontecimentos e palavras ( $\operatorname{Ef} 5.26$ ), por dons terrenos concedidos pelo Senhor (Jo 6.53-58), que nos ritos da igreja acontece o mistério da regeneração (Tt 3.5; 1Pd 1.23; 2.2; Jo 3.3-8), da santificação (Hb 12.9-11) e da união permanente com o Senhor (Jo 6.56-57) ${ }^{12}$ Deus serve-se de elementos como a água, o pão, o vinho e o óleo para conceder sua graça salvífica. Os ritos que expressam essas realidades são entendidos como "ações sagradas", sobretudo o Batismo e a Ceia, pelas quais Deus atua na vida dos fiéis.

\section{Atualidade da questão}

Mas para muitos, o que foi acima apresentado não é suficiente para mostrar que Cristo instituiu todos os sacramentos. O fato é que a Bíblia mostra que Jesus tem uma relação clara com alguns acontecimentos que embasam nele mesmo os sacramentos do Batismo (Mt 28.19), da Eucaristia (Mt 26.26; Mc 14.22; Lc 22.19) e da Penitência (Mt 16.19; 18.18; Jo 20.23). Com relação aos demais, há mais indícios implícitos do que indicações objetivas. E mesmo a instituição do Batismo e da Ceia por Cristo necessita de explicação. Teólogos afirmam que enquanto na Ceia está clara a ordem expressa por Cristo, e atestada em Paulo e Lucas, no caso do Batismo, porém, "somente se pode falar de uma instituição por Jesus ainda no sentido ampliado de que o batismo cristão possui seu fundamento no próprio Jesus, a saber, no fato de seu próprio batismo e na relação dele com sua paixão"'13. A instituição da Ceia fundamenta-se numa ordem do Jesus pré-pascal, enquanto o Batismo vem do Ressuscitado, conforme a tradição de Mt 28.19. O fato de a comunidade cristã ter o rito do Batismo como praxe para o ingresso na igreja significaria, para esses, mais uma cerimônia que ganha tradição na igreja do que propriamente uma instituição por Cristo. ${ }^{14}$

A dificuldade no entendimento da instituição dos sacramentos por Cristo tem levado os teólogos a entendê-los tanto em relação à igreja (católicos) como em rela-

${ }^{10}$ Cf. BOROBIO, 1990, p. 347.

${ }^{11}$ BOROBIO, 1990, p. 347.

${ }^{12}$ HOTZ, Robert. Sacramento/Sacramenti. In: CERETI, Giovanni (Org.). Dizionario del Movimento Ecumenico. Bolonha: EDB, 1994. p. 949.

${ }_{13}$ PANNENBERG, Wolfhart. Teologia Sistemática. São Paulo: Paulus; Academia Cristã, 2009. v. 3, p. 459.

${ }^{14}$ PANNENBERG, 2009, p. 459. 
ção à Palavra (evangélicos). Teólogos católicos afirmam que Jesus teria dado origem à igreja como "primeiro-sacramento", "sacramento originário", "sacramento fundamental", com base em Ef 3.3-10: "A instituição de um sacramento pode também ocorrer pelo simples fato de Cristo ter fundado a Igreja com o seu caráter de proto-sacramento"15. Os evangélicos criticam essa tese católica de "sacramentalização da igreja"16, entendendo a instituição dos sacramentos estreitamente relacionada com a Palavra: os sacramentos são sinais externos da promessa da salvação dada na Palavra. Assim, tanto católicos como evangélicos precisam continuar aprofundando suas pesquisas para, juntos, chegarem a um consenso sobre a instituição por Cristo dos sacramentos individuais.

Há quem proponha uma terceira via para explicar a origem dos sacramentos: buscam um significado amplo de "instituição", sem a exigência de encontrar em Jesus uma ordem explícita para cada sacramento. Bastaria, então, mostrar que os sacramentos remetem a Jesus e que desde os primórdios da igreja são realizados como continuidade das ações do próprio Jesus e no sentido da Páscoa. ${ }^{17}$ A questão aqui é que todas as expressões da fé, também nos chamados "sacramentais", remetem a Jesus, de modo que não se distingue devidamente os sacramentos da fé, propriamente ditos, de outras mediações. Além disso, essa tese não explica os sacramentos a partir da humanidade de Cristo, uma vez que entende ser unicamente a partir da páscoa que se percebe a ação do Espírito do Ressuscitado na igreja e nos sacramentos. ${ }^{18}$ De outro lado, a tese tem a vantagem de situar a origem dos sacramentos no mistério pascal de Cristo. Na Páscoa aparece também a origem trinitária dos sacramentos, eles são instituídos por Deus por meio de Cristo e no poder do Espírito. Assim, "permanece preservada a vinculação com a pessoa de Jesus e principalmente a ideia de uma outorga divina [...] (os sacramentos) não são meras invenções humanas, mas estabelecimentos do próprio Deus no contexto da revelação de sua salvação em Jesus Cristo" ${ }^{19}$. Nesse horizonte, aparecem oportunidades para o consenso sobre a instituição dos sacramentos por Cristo.

O que se pode concluir é que as diferentes igrejas concordam que os sacramentos são instituídos por Jesus Cristo: “A participação nos sacramentos da igreja é participação a Cristo mesmo. Ele instituiu os sacramentos" ${ }^{20}$. Mas essa afirmação é complexa. Uma coisa é compreender que Jesus tem relação com a realidade que o sacramento significa, por ele comunica sua graça. Outra coisa é dizer que foi Jesus quem instituiu este ou aquele sinal como um sacramento, excluindo outros. As igrejas não têm consenso sobre isso quando se trata do setenário sacramental. O diálogo continua.

15 RAHNER, Karl. La Iglesia y los Sacramentos. Barcelona: Herder, 1964. p. 44.

16 PANNENBERG, 2009, p. 461.

17 Ver essa discussão em PANNENBERG, 2009, p. 463-465.

18 CHAUVET, 1979, p. 237-252.

19 PANNENBERG, 2009, p. 464. Embora o autor trate aqui exclusivamente do batismo e da ceia, parece possível aplicar sua tese aos demais ritos entendidos por católicos e ortodoxos como sacramentos.

${ }^{20}$ COMISSÃO CATÓLICA-LUTERANA (Alemanha). Comunione nella parola e nel sacramento, n. 43. In: Enchiridion Oecumenicum. Bolonha: EDB, 2000. v. II, p. 619. 


\section{O número dos sacramentos}

A questão da instituição do sinal sacramental da fé cristã está diretamente ligada à questão do número dos sacramentos. Não há consenso sobre "quais" símbolos da fé foram instituídos por Cristo, pelo que a igreja os reconhece com uma dignidade sacramental. Isso exige compreender como é possível traduzir no conceito "sacramento" a realidade da graça de Cristo. Não se duvida que a experiência da graça excede os meios designados sacramentos, pois Deus não amarra seu poder salvador e sua graça aos sacramentos. Não se deve correr o risco de cristalizar a experiência cristã da graça, desviando-a da realidade original. Por isso não é tarefa fácil justificar na igreja uma prevalência dos sacramentos da fé em relação a outros sinais pelos quais também se faz a experiência da graça salvífica.

\section{Retomando a história}

Até o século XII, o termo "sacramento" era usado para designar muitas coisas além dos ritos sacramentais como Cristo, a Escritura, a igreja, a páscoa, a encarnação, a quaresma, entre outros. Havia mais ou menos sacramentos, e uma distinção entre sacramentos maiores (Batismo e Eucaristia) e sacramentos menores (os demais sacramentos), e entre esses sacramentos e os vários sinais sagrados que ajudam na relação com Deus, mas não transmitem a graça de forma sacramental. ${ }^{21}$

A afirmação do setenário queria, inicialmente, resolver situações específicas, e só com o tempo vai se afirmando como fé da igreja, num longo período que vai do século XI ao século XVI. A ideia de sete sacramentos foi se fortalecendo com os canonistas do século XII, como Estevão de Tournai (1128-1203) e Pedro Lombardo (11001160) com os comentários das Sententiae ou Tractatus. ${ }^{22}$ Mas era difícil o consenso nessa matéria, como o demonstra a necessidade de o papa Inocêncio III (1161-1216) exigir a afirmação do setenário na confissão de fé pedida aos valdenses em $1208^{23}$, o II Concílio de Lião (1274) exigir a afirmação do setenário na confissão de fé de Miguel Paleólogo (1224-1282) ${ }^{24}$, e o Concílio de Florença (1439) afirmar os sete sacramentos na fórmula de fé para a união entre católicos e ortodoxos armênios. ${ }^{25}$ Embora nesses casos não se pretendesse propor uma doutrina sacramental para a igreja universal, eles certamente contribuíram para a afirmação do setenário.

A partir do século XVI, Lutero e seus seguidores retomaram as dúvidas sobre quais são os sacramentos instituídos por Cristo, negando aqueles que não tinham nas Escrituras uma clara indicação por um gesto e uma ordem de Jesus. A consequência

21 BOROBIO, 1990, p. 293.

22 Para aprofundar esse fato, ver SANCHES, Jose; CASTILLO, Maria. Símbolos de Libertad. Teologia de los Sacramentos. Salamanca: Verdad e Imagem, 1981. p. 375-377.

23 DENZINGER, Heinrich; HÜNERMANN, Peter (DH). Enchiridion symbolorum definitionum et declarationum de rebus fidei et morum, n. 793-796. 2. ed. Bolonha: EDB, 1996.

${ }^{24} \mathrm{DH}$ n. 860.

${ }^{25}$ DH n. 1.311 
foi que a estrutura sacramental da igreja construída pela escolástica desabou. Os reformadores acabaram por afirmar como sacramentos apenas o Batismo e a Eucaristia. Mas eles oscilaram muito para afirmar apenas esses dois sacramentos. Lutero tinha grande apreço à Confissão, a ponto de fazer "exortação à confissão"26 e orientar "Como se deve ensinar as pessoas simples a se confessarem"27. O que ele questionava era mais o modo como a Confissão era realizada, a contrição baseada no temor, a capacidade da confissão oral de todos os pecados, a interpretação do "poder das chaves" confiado à igreja (Mt 16.19; 18.18; Jo 20.23). ${ }^{28}$ Melanchthon (1497-1560) afirma, nos Loci praecipui theologici (1559), como sacramentos também o perdão, o matrimônio e a ordem. ${ }^{29}$ Calvino (1509-1564) escreveu sobre o ministério ordenado:

Quanto à imposição das mãos, feita para introduzir os verdadeiros sacerdotes e ministros da igreja no seu estado, eu não me oponho que ela venha recebida como sacramento. Porque, em primeiro lugar, é uma cerimônia tomada da Escritura; e depois, como disse São Paulo, não é de fato inútil, mas é um sinal da graça espiritual de Deus (1Tm 4,14). Se não a coloquei junto com as outras duas, é porque não é ordinária e comum entre os fiéis, mas é destinada a uma função particular ${ }^{30}$.

Vê-se, ao menos nessas passagens, que os reformadores não negam radicalmente a "prática" ritual da igreja do seu tempo, embora destituam muitas delas da "dignidade" sacramental. O concílio de Trento reagiu condenando suas doutrinas e reafirmando o setenário sacramental, sua origem em Cristo e sua necessidade para a salvação. ${ }^{31}$ Estudiosos afirmam, porém, que quando Trento discutiu as teses dos reformadores sobre os sacramentos, classificou-as entre as que devem ser condenadas, como a afirmação que os sacramentos não foram instituídos por Cristo; as que não podem ser condenadas sem os devidos esclarecimentos, como o número dos sacramentos; e as que devem ser ignoradas, como a distinção entre os sacramentos da antiga lei e da nova lei. ${ }^{32} \mathrm{E}$ a afirmação de sete sacramentos, mais que dar uma interpretação exclu-

${ }^{26}$ LUTERO, Martinho. Catecismo Maior. In: Alegre: Concórdia, 2000. v. 7, p. 325-446, às p. 442-446.

${ }^{27}$ LUTERO, Martinho. Catecismo Menor. In:____ Obras selecionadas. São Leopoldo: Sinodal; Porto Alegre: Concórdia, 2000. v. 7, p. 447-470, às p. 462-464. Nos catecismos de Lutero, a confissão é colocada ao lado do batismo e da eucaristia, não definida como "sacramento" por não ter um sinal visível. Os artigos XI a XIII da Confissão de Augsburgo colocam a penitência com confissão e absolvição entre os sacramentos.

28 A CONFISSÃO de Augsburgo. Art. XXV. São Leopoldo: Sinodal, 1999.

29 Escreve Melanchthon: "Se o sacramento se acomoda também aos atos morais, pode-se dizer que o matrimônio é sacramento [...] Porque, além do mais, é imagem do amor de Cristo à sua esposa, à Igreja". MELANCHTHON, F. Loci praecipui theologici, apud BELLOSO Josep M. Rovira, Os Sacramentos - Símbolos do Espírito. São Paulo: Paulinas, 2005. p. 98. Ver agora: MELANCHTHON, Filipe. Loci Theologici. Tópicos Teológicos, de 1521: Edição crítica bilíngue, latim e português. Editado e traduzido por Eduardo Gross. São Leopoldo: Sinodal; EST, 2018.

30 Inst. IV,9, 28. CALVINO, João. As Institutas - Tratado da Religião Cristã. São Paulo: Casa Editora Presbiteriana, 1989. p. 445.

31 DH 1.601-1.604.

32 BOROBIO, 1990, p. 357. 
sivamente numérica, pretende oferecer "uma fixação numérica como a única possibilidade de manter o horizonte qualitativo simbólico da totalidade sacramental" ${ }^{33}$. A ênfase na interpretação numérica pretendia "evitar o nominalismo ou esvaziamento do sentido do sete", sem desconsiderar o valor simbólico e qualitativo do número sete. ${ }^{34}$

\section{Atualidade da questão}

Teólogos católicos contemporâneos matizam a questão numérica dos sacramentos. Mais importante que o valor aritmético, o número sete quer afirmar que esses sacramentos têm eficácia salvífica de forma única e distinta de outros sinais sacramentais. ${ }^{35}$ Além de afirmar que Cristo instituiu cada um dos sacramentos, o fundamental é afirmar "a orientação septiforme" ${ }^{36}$ da graça de Cristo. Mas na tradição católica o número sete não tem um significado abstrato ou apenas teórico. Estudiosos entendem que Trento afirmou sete sacramentos para, de um lado, com um número concreto de sinais da fé, fazer oposição ao nominalismo; por outro lado, o número tem um valor simbólico que expressa a totalidade sacramental, sem excluir a possibilidade que a graça possa ser comunicada também por outras formas. Assim, mais que fechado e excludente, o número sete deve ser interpretado num sentido aberto e flexível, esses sacramentos são a concentração de outras sacramentalidades, tendo como afirmação principal o fato de que "os sacramentos de Cristo se conformam ao modo de ser da pessoa humana" $" 37$.

Também na teologia evangélica a questão do número dos sacramentos não é fechada. Comentadores de Lutero entendem que os três sinais constitutivos da igreja presentes no Artigo VII da Confissão de Augsburgo (Palavra, Batismo e Ceia) não devem ser entendidos como um número fechado. Como visto acima, outras práticas rituais da igreja, como o perdão, o ministério pastoral, o matrimônio, o atendimento aos doentes, seriam sinais pelos quais se reconhece a igreja e são subordinados aos três principais. ${ }^{38}$ Esses não devem ser vistos isoladamente..$^{39}$ A expressão "satis est", no artigo 7 da Confissão de Augsburgo, não significa que nada mais há de sinais da fé cristã além dos três ali mencionados. Ali estão os suficientes, que levam a outros que os desdobram e explicitam: "A ampliação do número de sinais da igreja além do nú-

33 BOROBIO, 1990, p. 357.

${ }^{34}$ BOROBIO, 1990, p. 357.

35 "O essencial na afirmação do número sete não é o número, mas a afirmação de que os ritos eclesiásticos a que ele se refere, todos eles e apenas eles, têm de fato eficácia sacramental”. RAHNER, 1964, p. 61-62.

36 SCHILLEBEECKX, Edward. Cristo, sacramento do encontro com Deus: estudo teológico sobre a salvação mediante os sacramentos. Petrópolis: Vozes, 1967. p. 131-135.

37 BELLOSO, 2005, p. 18.

${ }^{38}$ No texto "Dos concílios e da Igreja" (1539), Lutero trata também da confissão e absolvição, dos ministérios entendidos como serviço, sobretudo o pastoral, da oração e louvor a Deus, da cruz e do sofrimento. LUTERO, Martinho. Como Reconhecer a Igreja Hoje (Dos concílios e da Igreja, $3^{\mathrm{a}}$ parte). São Leopoldo: Sinodal, 2001. p. 22-24.

${ }^{39}$ Melanchthon afirma a sacramentalidade de "toda obra ordenada por Deus à qual está anexa alguma promessa". E cita a oração, o perdão das injúrias, a esmola. MELANCHTHON, Philipp. Loci praecipui theologici, apud BELLOSO, 2005, p. 99. 
mero três aponta para o fato de que a palavra não se resume a si mesma, mas impulsiona para a comprovação na vida do cristão individual, da comunidade e do mundo"40.

Portanto o número dos sacramentos não é uma questão fechada, nem na teologia católica nem na teologia evangélica. Para os católicos, o setenário sacramental não quer excluir a possibilidade de Deus transmitir sua graça pelos meios e formas que bem entender, como a criação, as pessoas, a igreja, as Escrituras etc. Há uma sacramentalidade muito ampla, para quem tem fé, tudo fala de Deus. De outro lado, teólogos evangélicos perguntam se "porventura o mistério de Cristo é exposto na vida da igreja apenas nas duas cerimônias de batismo e santa ceia? Ou será que também se manifesta de forma comparável, como sinal, em outras 'execuções vivenciais' da igreja"? ${ }^{41}$. Para alguns, está aberta a possibilidade de incluir no conceito de sacramento outras ações com cunho de sinal, além do Batismo e da Ceia. O critério para isso é verificar se por essas ações se manifesta a presença do mistério da salvação em Cristo. Um "sinal sacramental" é toda "relação com a atuação e pessoa de Jesus de tal maneira que se possa declarar que nisso o próprio Jesus está presente" ${ }^{2}$. E tal pode ser verificado no perdão dos pecados, na unção dos enfermos, na confirmação, bem como em muitas ações da igreja, que são sinais da presença da salvação, conforme Mt 11.4s, que caracterizam a atuação de Jesus. Mesmo se não são "ações rituais com cunho de sinal", estão na dimensão de sinal "sacramental". ${ }^{43}$

\section{O setenário sacramental no diálogo ecumênico}

A questão é tratada nos diálogos oficiais das igrejas. No diálogo católico-luterano internacional, luteranos entendem:

Nem mesmo segundo a convicção luterana a ação do Senhor que comunica a graça se realiza somente na palavra pregada e na administração do batismo e da eucaristia. A confissão, o diálogo pastoral, como também a ordenação, a confirmação e o matrimônio religioso são entendidos como atos nos quais a graça é prometida e dada aos homens, também se em geral se entende que tais atos não são de considerar sacramentos no sentido pleno do termo ${ }^{44}$.

No diálogo católico-luterano da Alemanha, luteranos entendem que nessa controvérsia aparece uma compreensão própria da graça concedida pelo sacramento

${ }^{40}$ BAYER, Oswald. A Teologia de Martin Lutero. São Leopoldo: Sinodal, 2007. p. 189.

41 PANNENBERG, 2009, p. 478.

42 PANNENBERG, 2009, p. 478.

43 PANNENBERG, 2009, p. 478.

${ }^{44}$ COMISSÃO CATÓLICA LUTERANA. Vie verso La comunione, n. 19. In: Enchiridion Oecumenicum. Bolonha: EDB, 1994. v. I, p. 662. Tradução própria. "Nemmeno secondo la convinzione luterana la azione del Signore que comunica la grazia si compie sollo nella parola predicata e nell' aministrazione del batesimo e dell'eucaristia. La confessione, il dialogo pastorale, come pure l'ordinazione, la confermazione ed il matrimonio religioso sono intesi come atti nei qualli la grazia è promessa e accordata agli uomini, anche se in genere si ritiene Che tali atti non sono da considerare dei sacramenti nel senso pieno del termine". 
como remissão dos pecados, vida cristã e eclesial e santificação: "Com essa definição podem ser incluídos o batismo, a eucaristia e a absolvição, mesmo se na penitência não se tenha um sinal comparável à água, ou ao pão e ao vinho"45. Afirmam: "Se o conceito de sacramento vem ulteriormente expresso no sentido de $C A$ e $A C A X I I I$, a igreja evangélica luterana não tem dificuldade substancial para definir a penitência, ou mais precisamente a absolvição, um sacramento"46.

O Grupo de Dombes dá significativos passos para uma afirmação ecumênica a respeito:

Do lado católico, a reflexão teológica contemporânea enfatiza cada vez mais as diferenças existentes entre os ritos que constituem o setenário. Entre uns e outros, o termo sacramento aparece como analógico. Além disso, fiel a uma convicção que sempre viu na eucaristia o auge do organismo sacramental, ela acentua que o batismo e a eucaristia são os sacramentos maiores e primordiais em redor dos quais se organizam outros sacramentos. Por conseguinte, é legítimo falar de uma "hierarquia de sacramentos" do mesmo modo como o Concílio Vaticano II falou de uma "hierarquia das verdades"

\section{O documento propõe:}

À medida que o termo sacramento dificilmente pode ser descartado, propomos um vocabulário que mantenha a unidade e a diferença; por exemplo, sacramentos para o batismo e a eucaristia, e atos sacramentais para as outras celebrações. Isso sem excluir a possibilidade de um termo comum correspondente ao setenário ${ }^{48}$.

Entende-se que há uma hierarquia nos sacramentos e por essa razão julga-se válida a distinção entre "sacramentos maiores ou principais" e "sacramentos menores ou secundários". ${ }^{49}$ Surge a hipótese de usar um termo comum e também expressões diferentes para os sacramentos, reconhecendo que 'todos são 'sacramento', mas que,

${ }^{45}$ COMISSÃO CATÓLICA-LUTERANA (Alemanha). Comunione nella parola e nel sacramento, n. 44. In: Enchiridion Oecumenicum. Bolonha: EDB, 2000. v. II, p. 621.

${ }^{46}$ COMISSÃO CATÓLICA-LUTERANA (Alemanha). Comunione nella parola e nel sacramento, n. 46. In: Enchiridion Oecumenicum. Bolonha: EDB, 2000. v. II, p. 623.

${ }^{47}$ GRUPO DE DOMBES. Lo Spirito Santo, la chiesa e i sacramenti, n. 29. In: Enchiridion Oecumenicum. Bolonha: EDB, 2000. v. II, p. 396. Tradução própria. "Da parte cattolica, la riflessione teologica contemporanea mette sempre più in evidenza le differenze tra i riti che costituiscono il settenario. Tra gli uni e gli altri il termine 'sacramento' appare analógico. Inoltre, fedele a uma convinzione che ha sempre visto nell'eucaristia l'apice del organismo sacramentale, essa sottolinea che il battesimo e l'eucaristia sono i sacramenti maggiori e primordiali attorno ai quali appaiono organizzati gli altri. È dunque legittimo parlare di uma 'gerarchia dei sacramenti' allo stesso modo in cui il Vaticano II hà parlato di uma 'gerarchia delle verità'”.

48 GRUPO DE DOMBES. Lo Spirito Santo, la chiesa e i sacramenti, n. 32. In: Enchiridion Oecumenicum. Bolonha: EDB, 2000. v. II, p. 399. Tradução própria. "Nella misura in cui il termine sacramento può difficilmente essere eliminato, proponiamo una termnologia che potrebbe esprimere l'unità e la differenza, per esempio, sacramenti per il battesimo e l'eucaristia, e atti sacramentali per le altre celebrazione. Ciò senza escludere l'opportunità di un termine che abbraci il settenario".

49 CONGAR, Yves Marie. La idea de los sacramentos mayores o principales. Concilium, Petrópolis, n. 31, p. 24-37, 1968. 
entre eles, há um mais sacramental ou menos sacramental [...] cada um é sacramento à sua maneira" 50 . A centralidade pertence à Eucaristia. $O$ termo sacramento é aplicado a diversas realidades com elementos comuns e diferenciadores de sacramentalidade, sendo, portanto, um conceito análogo e não unívoco. ${ }^{51} \mathrm{O}$ caráter analógico do conceito sacramento permite ver significados diferentes quando aplicado a realidades como Cristo, igreja, ser humano, criação, palavra etc. A distinção entre os sete sacramentos decorre da forma mais explícita ou não na Bíblia da sua relação com Cristo, sua realização eclesiológica, seu enraizamento vital, suas vicissitudes históricas de configuração e reconhecimento, sua centralidade pascal, sua estrutura simbólica. ${ }^{52}$ Trento condenou a tese protestante segundo a qual "nenhum sacramento é mais digno do que outro em nenhum aspecto" 53 . Como visto, a tradição da igreja deu primazia ao Batismo e à Eucaristia como os sinais da fé mais explicitamente testemunhados pelas Escrituras, os que por sua estrutura simbólica melhor expressam o mistério pascal, ocupam um lugar privilegiado na constituição da igreja e se erigem como verdadeiros pilares da vida cristã. ${ }^{54}$

Assim como a perspectiva católica pode distinguir entre "sacramentos maiores" e "sacramentos menores" e "afirma como prioridade a concordância de doutrina relativa aos sacramentos maiores" $"$, evangélicos podem entender que

a Igreja evangélica luterana não contestará nunca que o Senhor da igreja atue também em outros modos que não são os sacramentos em sentido estrito [...] Aquelas ações litúrgicas da Igreja católica romana, que não são afirmadas entre os sacramentos da Igreja evangélica luterana, podem representar uma advertência para esta última, para que essa repense o que são na igreja as ações de bênção, e considere de novo seriamente o fato que os escritos confessionais evangélicos luteranos não fixam nunca um número preciso de sacramentos, mas certamente colocam em evidência a posição singular do batismo, da ceia do Senhor e da absolvição ${ }^{56}$.

Desse modo, "podemos afirmar que todos os outros sacramentos, todos os sacramentais e todas as ações de bênção em vista do estado do cristão individual

50 BOROBIO, 1990, p. 360.

${ }^{51}$ BOROBIO, Giovanni. Historia y Teología Comparada de los Sacramentos. El principio de la analogía sacramental. Salamanca: Sígueme, 2012. p. 13-22.

52 BOROBIO, 1990, p. 360.

${ }^{53} \mathrm{DH} 1603$.

${ }^{54}$ CONGAR, 1968, p. 30.

55 COMISSÃO CATÓLICA-LUTERANA (Alemanha). Comunione nella parola e nel sacramento, n. 50. In: Enchiridion Oecumenicum. Bolonha: EDB, 2000. v. II, p. 627.

${ }^{56}$ COMISSÃO CATÓLICA-LUTERANA (Alemanha). Comunione nella parola e nel sacramento, n. 50. In: Enchiridion Oecumenicum. Bolonha: EDB, 2000. v. II, p. 627. Tradução própria. "la Chiesa evangelica non contestarà mai che il Signore della chiesa opere anche in altri modi che non siano i sacramenti in senso ristretto [...] Quelle azioni liturgiche della Chiesa cattolica romana che non sono annoverate fra i sacramenti della Chiesa evangelica luterana, possono representare un monito per quest ultima áffinchè questa rimediti che cosa sono nella chiesa le azioni di benedizione, e considere di nuovo seriamente il fatto che gli scritti confessionali evangelici luterani non fissano mai un numero preciso di sacramenti ma certamente mettono in evidenza la posizione singolare del battesimo, della cena del'Signore e dell'assoluzione". 
cumprem, renovam, tornam certo ou concreto o dom fundamental do santo batismo, mediante o qual Cristo nos colocou em comunhão com ele, na comunhão da igreja"'57.

\section{Considerações conclusivas}

Um passo dado para o entendimento comum sobre quantos e quais são os sacramentos da fé cristã é o consenso de que para que haja comunhão na fé em Cristo não há necessidade de se obter uniformidade na forma de celebrar a fé. No contexto do Concílio Vaticano II foi feita essa distinção na teologia católica, afirmando que "uma coisa é a substância do 'depositum fidei', isto é, as verdades contidas na nossa doutrina, e outra é a formulação com que são enunciadas" ${ }^{58}$. Outra importante contribuição do Vaticano II para o diálogo ecumênico é a afirmação da existência de uma hierarquia de verdades na doutrina católica (UR 11), nem todas estão no mesmo nível em sua relação com o núcleo cristológico e trinitário da fé cristã. Aplicando esse ensinamento conciliar à teologia sacramental, mesmo que todos os sacramentos tenham relação com Cristo, alguns explicitam essa relação de forma mais direta do que outros. Além disso, o nível e a forma da relação entre Cristo e os sacramentos são diferenciados em cada um deles. Essa constatação favorece o diálogo ecumênico sobre os sacramentos, priorizando no debate aqueles sacramentos nos quais se verifica um vínculo mais objetivo com Cristo. Do lado evangélico, também a Confissão de Augsburgo entende que "Para a verdadeira unidade da igreja cristã não é necessário que em toda parte se observem cerimônias uniformes instituídas pelos homens" 59 . A comunhão na fé pode ter expressões diversas, pois a própria natureza da fé, como algo dinâmico, gratuito e contextualizado, exige expressões plurais para ser vivida por cada indivíduo e cada comunidade. Assim, os sinais da fé podem ser diferentes, pois a própria fé tem uma dinâmica específica em cada pessoa, cada situação, cada tempo e lugar.

Essa questão é eclesiológica, uma vez que os sacramentos são entendidos como constitutivos da igreja. Mas o que, em última instância, caracteriza o ser igreja é a formação de uma comunidade de fé e de testemunho convicto do Evangelho de Jesus Cristo. A celebração sacramental da fé da igreja é uma expressão privilegiada e necessária da experiência de fé, mas note-se que essa experiência já foi vivida antes da celebração, o que dá a essa uma natureza de mediação, "fonte" ou "ápice" da expressão da fé, sem com isso condicionar a veracidade da experiência da fé ao meio pelo qual ela foi feita ou à forma de celebrar. Desse modo, a resposta às questões relativas aos sinais sacramentais da fé cristã vai além da teologia dos sacramentos, trata-se de uma compreensão da doutrina da graça e suas mediações. E a questão torna-se, então, cristológica: trata-se de entender como Cristo atua no mundo, dispensando sua graça

${ }^{57}$ COMISSÃO CATÓLICA-LUTERANA (Alemanha). Comunione nella parola e nel sacramento n. 50. In: Enchiridion Oecumenicum. Bolonha: EDB, 2000. v. II, p. 628.

58 JOÃO XXIII. Discurso na abertura solene do concílio, aos 11/10/1962. CONCILIO VATICANO II. Documentos do Concílio Ecumênico Vaticano II. 4. ed. São Paulo: Paulus, 2007. p. 28.

${ }_{59}$ A CONFISSÃO de Augsburgo, art. VII. 
salvífica. A graça crística não se manifesta apenas pela graça sacramental, de modo que não há como afirmar que há carências na recepção da graça de Cristo aos cristãos que em suas igrejas não têm acesso a alguns meios considerados sacramentos em outras igrejas. O que caracteriza a plenitude na experiência da graça é a possibilidade da salvação em Cristo, mais que o uso dos meios de salvação. E a soteriologia não se resume na sacramentaria. Temos, enfim, uma questão pneumatológica: os sacramentos são mediações da ação do Espírito que atua possibilitando a acolhida do dom da graça. E como o Espírito atua pelos sacramentos e também os transcende, esse fato torna-se um convite às igrejas para que ao afirmarem sua identidade cristã e eclesial enraizada nos sacramentos, também os coloquem sob a ação do Espírito, que as ajuda na transcendência do estatuto teológico que sustenta a doutrina sacramental em cada uma delas. Dessa forma o Espírito trabalha as igrejas para que possam, algum dia, celebrar nos mesmos sacramentos o conteúdo da mesma fé em Cristo.

\section{Referências}

A CONFISSÃO de Augsburgo. São Leopoldo: Sinodal, 1999.

AGOSTINHO. A Doutrina Cristã. 2. ed. São Paulo: Paulus, 2007.

AQUINO, Tomás de. Summa Theologica. COSTA, Rovílio et al. Suma Teológica. Terceira Parte. 2. ed. Caxias do Sul: Livraria Sulina Editora, 1980.

BAYER, Oswald. A Teologia de Martin Lutero. São Leopoldo: Sinodal, 2007.

BELLOSO Josep M. Rovira. Os Sacramentos - Símbolos do Espírito. São Paulo: Paulinas, 2005. BOROBIO, Gionisio. Da celebração à teologia: que é um sacramento?. In: BOROBIO, Gionisio et al. A celebração na Igreja - Liturgia e sacramentologia fundamental. São Paulo: Loyola, 1990. v. I, p. 283-424.

BOROBIO, Giovanni. Historia y Teología Comparada de los Sacramentos. El principio de la analogía sacramental. Salamanca: Sígueme, 2012.

CALVINO, João. As Institutas - Tratado da Religião Cristã. São Paulo: Casa Editora Presbiteriana, 1989.

CHAUVET, Louis-Marie. Du Symbolique au Symbole. Essai sur les sacrements. Paris: Edition du Cerf, 1979.

COMISSÃO CATÓLICA LUTERANA. Vie verso la comunione. In: Enchiridion Oecumenicum. Bolonha: EDB, 1994. v. I, p. 654-692.

COMISSÃO CATÓLICA-LUTERANA(Alemanha). Comunione nella parola e nel sacramento. In: Enchiridion Oecumenicum. Bolonha: EDB, 2000. v. II, p. 574-678.

CONGAR, Yves Marie. La idea de los sacramentos mayores o principales. Concilium, Petrópolis, n. 31, p. 24-37, 1968.

COSTA, Rovílio et al. Suma Teológica. Terceira Parte. 2. ed. Caxias do Sul: Livraria Sulina Editora, 1980.

FABER, Eva-Maria. Doutrina Católica dos Sacramentos. São Paulo: Loyola, 2008.

GRUPO DE DOMBES. Lo Spirito Santo, la chiesa e i sacramenti. In: Enchiridion Oecumenicum. Bolonha: EDB, 2000. v. II, p. 381-427.

HOTZ, Robert. Sacramento/Sacramenti. In: CERETI, Giovani (Org.). Dizionario del Movimento Ecumenico. Bolonha: EDB, 1994. p. 948-952.

JOÃO XXIII. Discurso na abertura solene do concílio, aos 11/10/1962. Documentos do Concílio Ecumênico Vaticano II. 4. ed. São Paulo: Paulus, 2007. p. 21-32. 
LUTERO, Martinho. Catecismo Maior. In: Obras selecionadas. São Leopoldo: Sinodal; Porto Alegre: Concórdia, 2000. v. 7, p. 325-446.

LUTERO, Martinho. Catecismo Menor. In: In: . Obras selecionadas. São Leopoldo: Sinodal; Porto Alegre: Concórdia, 2000. v. 7, p. $\overline{447-469}$.

MARSILI, Salvatore. Sinais do Mistério de Cristo. Teologia litúrgica dos sacramentos, espiritualidade e ano litúrgico. São Paulo: Paulinas, 2010.

MELANCHTHON, Filipe. Loci Theologici. Tópicos Teológicos, de 1521: Edição crítica bilíngue, latim e português. Editado e traduzido por Eduardo Gross. São Leopoldo: Sinodal; EST, 2018. PANNENBERG, Wolfhart. Teologia Sistemática. São Paulo: Paulus; Academia Cristã, 2009. v. 3. RAHNER, Karl. La Iglesia y los sacramentos. Barcelona: Herder, 1964.

SANCHES, José Maria Castillo. Símbolos de Libertad. Teologia de los Sacramentos. Salamanca: Verdad e Imagen, 1981.

SCHILLEBEECKX, Edward. Cristo, sacramento do encontro com Deus: estudo teológico sobre a salvação mediante os sacramentos. Petrópolis: Vozes, 1967.

VERGOTE, Antoine. La realisation symbolique dans l'expresion cultuelle. La Maison-Dieu, Paris, n. 111, p. 110-131, primeiro trimestre 1972. 